\title{
A NeuroDesign Model for IS Research
}

\author{
Alan R. Hevner \\ University of South Florida, \\ Tampa, FL, USA \\ ahevner@usf.edu
}

Rosann Webb Collins University of South Florida, Tampa, FL, USA

rwcollins@usf.edu

\author{
Christopher Davis \\ University of South Florida, \\ St. Petersburg, FL, USA \\ davisc@mail.usf.edu
}

\section{T. Grandon Gill University of South Florida, Tampa, FL, USA grandon@usf.edu}

\begin{abstract}
The constructive (i.e. Build) activity in Design Research is where human cognitive (e.g., complexity, creativity, control) and social (e.g., collaboration) activities contribute to the design of novel artifacts that improve the human condition. In this essay, we model the design activity as an iterative process with flows connecting external and internal environments and problem and solution spaces. The design team performs within this process through cognitive interactions at critical points in the flow in order to structure the design problem, produce novel design candidates, manage the refinement of the best candidates into use artifacts, and achieve consensus among the design team as well as stakeholders. The model provides a basis to 'broker' and align neuroscientific theory and design research in the Information Systems (IS) field and, by doing so, within the broader informing science transdiscipline. The emphasis in the model on the interplay of 'doing' tasks and 'making' sense focuses directly on the task at hand and in mind. These iterations are manifest in four interactions, each of which has a set of important cognitive challenges which we explore. Use of the model to guide NeuroDesign research presents a number of fruitful opportunities to extend the use of neuroimaging techniques in design research beyond the evaluation of information technology (IT) artifacts. The model also highlights the potential of design as an empirical context to identify, frame, and address some of the limitations of prior studies of complexity, creativity, control, and collaboration that, to date, have stymied mainstream neuroscience.
\end{abstract}

Keywords: Design research, Neuroscience, NeuroIS, NeuroDesign, Design artifacts, Complexity, Creativity, Control, Collaboration

Material published as part of this publication, either on-line or in print, is copyrighted by the Informing Science Institute. Permission to make digital or paper copy of part or all of these works for personal or classroom use is granted without fee provided that the copies are not made or distributed for profit or commercial advantage AND that copies 1) bear this notice in full and 2) give the full citation on the first page. It is permissible to abstract these works so long as credit is given. To copy in all other cases or to republish or to post on a server or to redistribute to lists requires specific permission and payment of a fee. Contact Publisher@InformingScience.org to request redistribution permission.

\section{Introduction}

Human progress occurs when creative new ideas are realized in design artifacts (products and services) and markets are formed to produce, trade, and use these artifacts in efficient and effective ways (Ridley, 2010). While past thinking has considered inspiration and invention as the somewhat arbitrary products of great 
minds (e.g., Newton, Edison, Einstein, Jobs), the growing field of neuroscience is advancing our understanding of how the human brain generates new ideas. At the same time, the information revolution' has radically changed the ways in which we view and interact with our world. Thus, we have reached a tipping point where the fields of neuroscience and information technology (IT) are able to collaborate to identify and frame fundamental questions about the relationships between creativity, design, innovation, and research. The goals of such studies could include the development of new neuroscience models of creativity, new paradigms for designing IT artifacts, new approaches for education to optimize creative design thinking, and the development of creativity-enhancing IT tools for specific application domains.

This is a dynamic environment where socio-cognitive acts are mediated by information technologies that are at the same time increasingly ubiquitous and sophisticated. Design opportunities and challenges are no longer the exclusive preserve of experts.

\section{Research Domains}

It is against this backdrop that we explore the synergistic relationship of design research and neuroscience and the opportunities and challenges it presents in the information systems (IS) and IT contexts.

\section{Design Research}

The Design Research paradigm has its roots in the sciences of the artificial (Simon, 1996). It is fundamentally a problem-solving paradigm. Design research seeks to enhance human knowledge with the creation of innovative, useful artifacts. These artifacts embody the ideas, practices, technical capabilities, and products through which information systems (IS) can be efficiently developed and effectively used. The results include both the newly designed artifact and a fuller understanding of the theories of why the artifact is an invention or an improvement to the relevant application context (Hevner \& Chatterjee, 2010; Hevner, March, Park, \& Ram, 2004; Kuechler \& Vaishnavi, 2008; Winter, 2008).

To achieve a true understanding of and appreciation for the design research paradigm, an important dichotomy must be faced. Design is both a process and a product. It describes the world as acted upon (processes) and the world as sensed (artifacts). This view of design supports a problem-solving paradigm that continuously shifts perspective between design processes and designed artifacts for the same complex problem. The design process is a sequence of activities tapping a range of expertise that produces an innovative product (i.e., the design artifact). The evaluation of the artifact then provides feedback information and a better understanding of the problem in order to improve the qualities of both the product and the design process. This build-and-evaluate loop is typically iterated a number of times before the final design artifact is released into an application context for further evaluation through field study. During this creative process, the researcher must be cognizant of evolving both the design process and the design artifact as part of the research.

Design activities are central to most applied disciplines. Research in design has a long history in many fields including architecture, engineering, education, psychology, and the fine arts (Cross, 2001). The information systems (IS) field since its advent in the late 1940s has appropriated many of the ideas, concepts, and methods of design science that have originated in these other disciplines. However, IS as composed of inherently mutable and adaptable hardware, software, telecommunications, and human interfaces provides many unique and challenging design problems that call for new, creative ideas and discovery. IS artifacts are implemented within an application context (e.g., a business organization) for the purpose of improving the effectiveness and efficiency of that context. The utility of the artifact and the characteristics of the application - its 
work systems, its people, and its development and implementation methodologies - together determine the extent to which that purpose is achieved. Researchers produce new ideas that enhance generative capacity (Avital \& Te'eni, 2009) and improve the ability of human organizations to adapt and succeed in the presence of changing environments. These generative ideas are then communicated as knowledge to the various IS communities (Baskerville, 2008; Gregor \& Hevner, 2013).

\section{Neurols}

Researchers in IS have recently expanded their experimental toolset to include methods of cognitive neuroscience (Dimoka, Pavlou, \& Davis, 2011). The use of neuroscience to investigate research questions in information systems (termed NeuroIS) has grown rapidly with the availability of methods and tools adapted to IS research and application environments. As stated by Riedl et al. (2010):

NeuroIS is a subfield in the IS literature that relies on neuroscience and neurophysiological theories and tools to better understand the development, use, and impact of information technologies (IT). NeuroIS seeks to contribute to (i) the development of new theories that make possible accurate predictions of IT-related behaviors, and (ii) the design of IT artifacts that positively affect economic and non-economic variables (e.g., productivity, satisfaction, adoption, and well-being).

We note that this definition appropriately highlights the research applications of neuroscience to the study of both the construction and use of the IT artifact. Viewed in the design research framework (Figure 1), there are key opportunities to use neuroscience methods and tools to facilitate and monitor the creative processes that generate and build the artifact, to evaluate the evolving artifact in the lab setting, to evaluate a released artifact in a field setting, and to provide some theoretic cohesion.

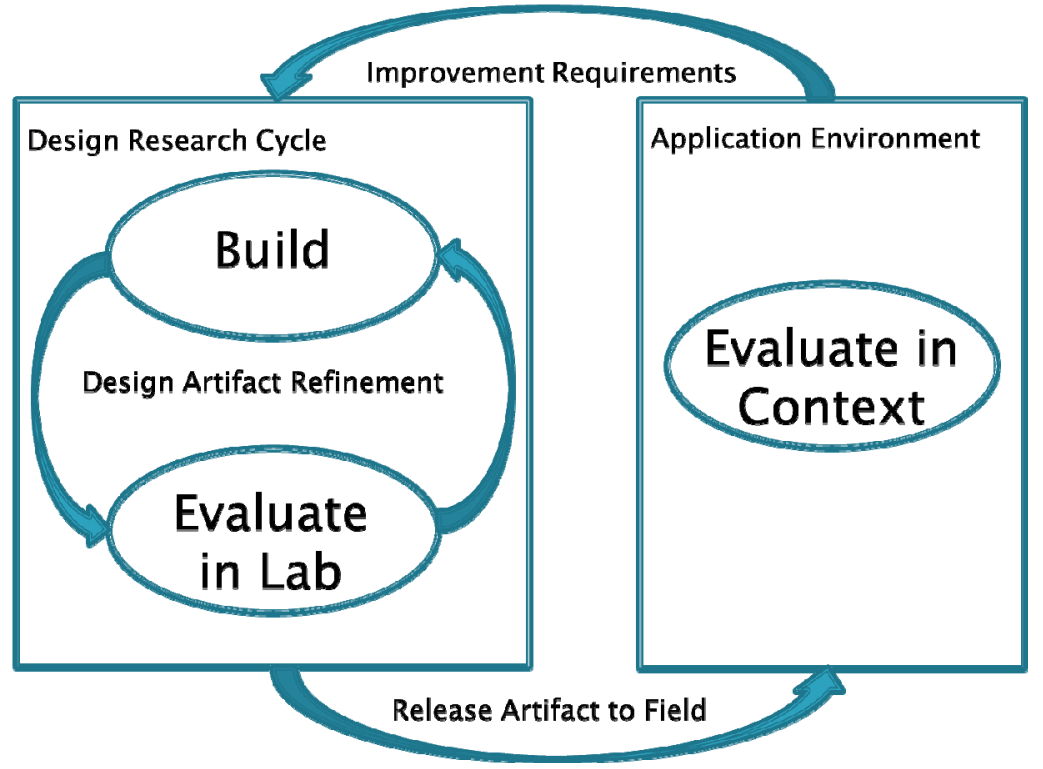

Figure 1: Neuroscience Opportunities in Design Research

The extant literature in NeuroIS focuses almost exclusively on the application of neuroscience for the evaluation of IT artifacts in an application context as seen in the following examples. Riedl (2009) examines the preference for object-oriented or control-flow programming languages. Technology acceptance using the TAM (F. Davis, 1989) has been studied by Dimoka and Davis 
(2008) and Dimoka et al. (2011). Gender differences in the use of technology and gender differences in trust in IT applications are explored in Dimoka et al. (2009) and Dimoka (2010). Glimcher, Fehr, Camerer, and Poldrack (2009) provide insights into brain processing underlying the use of decision support systems. In all of these projects, the evaluated IT artifact is well-known and had been previously established as useful in the application context. However, to date, there has been an imbalance between emphasis on evaluation of what Avital and Te'eni (2009) call 'generative fit' - the focus on the application context - and 'generative capacity'.

\section{NeuroDesign}

Very little NeuroIS research has studied the cognitive tasks of performing design Build activities (Vom Brocke, Riedl, \& Leger, 2012). We recognize the existence of a vast neuroscience literature examining the locations in the brain that are activated by the processes of creativity, insight, design, communication, collaboration, and control (e.g. Dietrich, 2004; Seidel Müller-Wienbergen, \& Becker, 2010). Our aim in this essay is not to exhaustively plumb such depths but rather to initiate an investigation into how to apply this extensive neuroscience knowledge base to the design research activities of building innovative IT artifacts. We develop a conceptual model of the design activity that highlights four key cognitive activities essential to successful design research. The model strives to align the epistemological challenges evident in mainstream neuroscience with the specific opportunities that neurophysiological imaging techniques present the design researcher. Our model does not present a meta-analysis per se (such analyses are ongoing in both neuroscience (Dietrich \& Kanso, 2010) and IS (Seidel et al., 2010)) but rather a framework for reconciliation of the theoretic perspectives and empirical lenses that have guided work in these disciplines to date.

A small set of selected references to neuroscience studies is used to illustrate potential NeuroDesign connections. We conclude with an analysis of the synergies between the design research methods and neuroscience and how these synergies have the potential to enable exciting new research directions in NeuroDesign.

\section{A Neuroscience Model of Design}

As a guide for aligning design research with neuroscience studies, we propose a conceptual model of design (Figure 2). The key structure of the model is the $2 \times 2$ description of the design process. The $\mathrm{x}$-axis distinguishes the External (Task) Environment from the Internal (Cognitive) Environment while the y-axis separates the Problem Space from the Solution Space.

- External (Task) Environment: This is the context of the design problem that has been presented. It includes an objectively determined but largely unknowable design fitness landscape that is independent of how the design is performed and exerts constraints on the problem and solution spaces.

- Internal (Cognitive) Environment: This is where human cognitive facilities perform the design processes needed to produce a satisfactory design solution. Neuroscience tools and techniques are applicable in this environment.

- Problem Space: This space supports the description of the design problem in the real world and the collection of representations, rules, and mappings that exists, individual and collectively, within the minds of the designers.

- Solution Space: This space enables production of design artifacts that move from the cognitive environment (because their purpose is often to facilitate communication and recall, such as a plan or prototype) to the external environment (because they are real). 


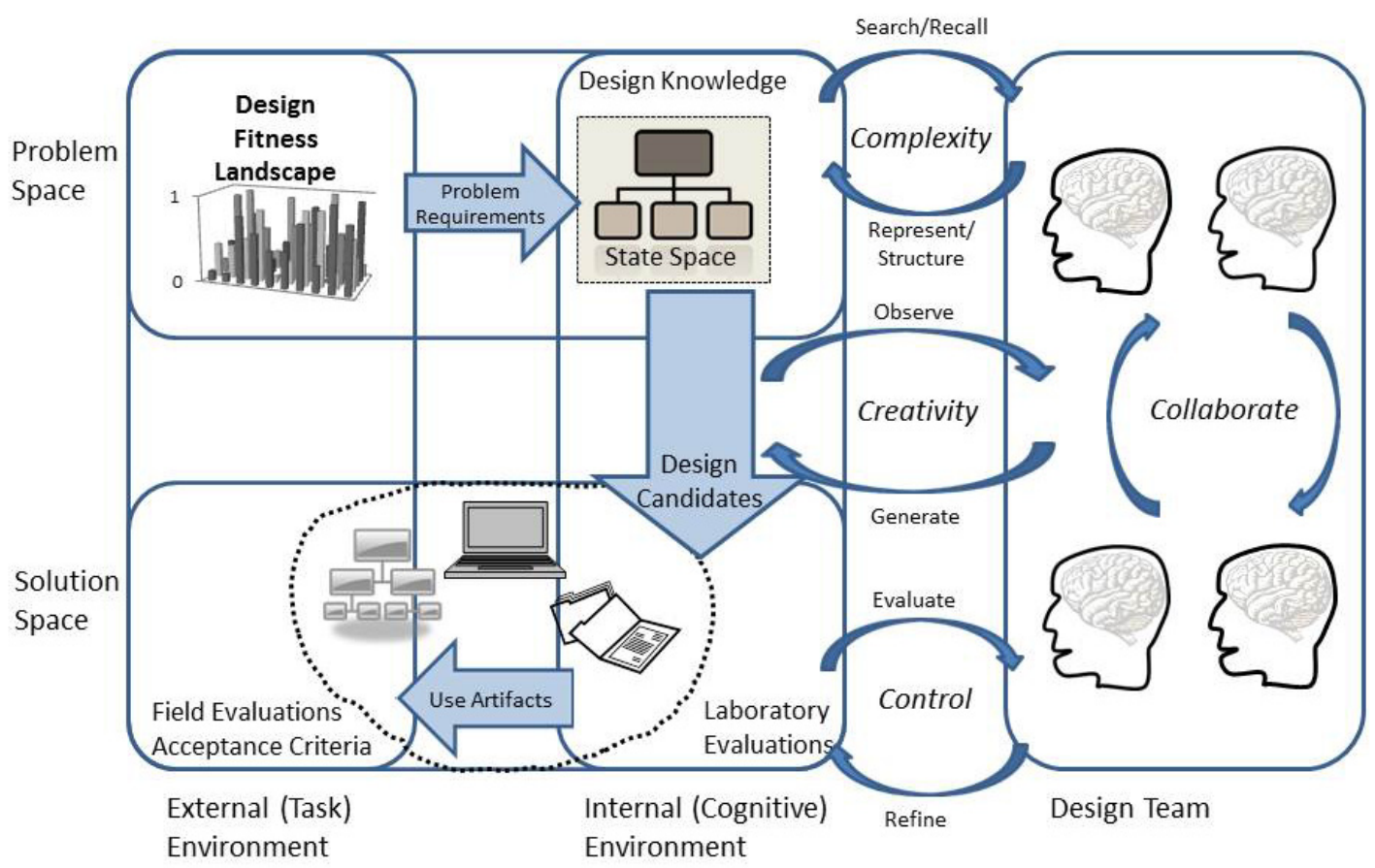

Figure 2: NeuroDesign Model

We model the design activity as an iterative process with three key flows: (1) from an external problem space to an internal problem space via problem requirements; (2) from the internal problem space to an internal solution space via candidate designs; and (3) from the internal solution space to an external solution space via use artifacts. The human design team performs the design tasks via interactions with the internal environment of the design activity. They act within this process through cognitive interactions at critical points in the flow:

1. Structure Problem - What cognitive activities address the complexities of the problem space? How does the brain search the problem statement for potential solution patterns while finding effective representations of problem structure?

2. Produce Novelty - How does the brain create new ideas for the production of innovative design candidates?

3. Manage Refinement - How does the brain control the assessment of candidate designs and search for the 'best' designs to instantiate as use artifacts?

4. Achieve Consensus - How do humans collaborate with others on the design team and with design stakeholders throughout the design process?

Our interest in NeuroDesign from an IS perspective, as shown in Figure 2, can be framed in terms of a better understanding of how designers interact with the problem space, the solution space, and with other designers in particular ways. (Note that we do not focus on understanding how the brain handles design problems. To the extent that it is a valid research agenda, this question seems much more likely to be of value to neuroscientists). For design research in IS, we pose the following important practical reasons for exploring what goes on inside the designer's brain.

- Observed design behaviors appear to violate "rational" (i.e. purely symbolic) views on how design should be conducted. For example, Ethiraj, Levinthal, and Roy (2008) observe that designers may choose to develop highly modular designs that are easily imi- 
tated whereas more innovative, less modular designs provide superior long term advantage over competitors. Such thinking parallels the behavioral economics research stream established by Kahneman (2011) and Ariely (2008) with respect to decision-making. If we were to better understand such design behaviors, we might be able to train individuals to be better designers by helping them learn to recognize common pitfalls.

- Different designers appear to follow very different paths when confronted with the same design problem - but cannot explain why. If we could understand these different approaches it might help us attain a better fit between designers and the types of problems we give them, since different types of design problems might be better served by correspondingly different design styles.

- What stopping rules do designers use in the design process to move design candidates from the problem space to the solution space and to move use artifacts from the internal environment to the external environment? (Browne \& Pitts, 2004). Considerable lost time and effort is spent in useless brainstorming and evaluations of designs that are infeasible or clearly sub-optimal. At the same time, potentially good candidate solutions may be lost in the 'fog'; their capacity for generative fit (per Avital \& Te'eni, 2009) unrecognized by evaluative scales and frames of reference that obscure them.

- The make-up of a design team appears to have a significant influence on the resulting design artifacts produced. How do issues like diversity and personality traits (e.g., conflict behavior) impact the collaborative performance of design teams? For example, Weedman's (2008) study of design collaboration between earth and computer scientists finds difficulties from the different perspectives of collaborators, such as differing levels of tolerance for ambiguity. Understanding these collaboration challenges would help in the formation and training of effective teams.

The model emphasizes the iterative interplay of action and interpretation (doing and making sense) rather than merely the influence of evaluation on choice (Weick, Sutcliffe, \& Obstfeld, 2005 , p. 409). The model provides a basis to 'broker' and align neuroscientific theory and IS design research. The emphasis on the design Build process provides a tenable empirical focus but without the dependence on reified artifacts-in-use - as has been the case to date in NeuroIS. The emphasis in the model on the interplay of 'doing' tasks and 'making' sense focuses directly on the task at hand and in mind. These iterations are manifest in the four interactions, each of which has a set of important cognitive challenges which we subsequently explore. Use of the model to guide NeuroDesign research presents a number of fruitful opportunities to leverage neuroimaging techniques and findings in design research beyond the evaluation of IT artifacts. The model also highlights the potential of design as an empirical context to identify, frame, and address some of the limitations of prior studies of complexity, creativity, control and collaboration that, to date, have stymied mainstream neuroscience.

The next four sections explore in more detail each of the highlighted cognitive challenges of the design Build activity. For each of the challenges, we describe its role in the model's design flow, provide a selected illustration of findings in the neuroscience literature, and pose several key research questions.

\section{Structuring the Problem - Complexity and Design}

One of the major factors influencing IS design is complexity. As seen in Figure 2, the first challenge a design team faces is the representation of the complex problem into a format that can be understood and manipulated. Designers may react to complexity in the design task in many different ways. They may choose to decompose the system into subsystems, each of which then becomes the basis of its own task. They may choose to approach the problem iteratively, using the 
repetitive build-evaluate cycles that are typical of agile programming. They may choose to reframe the problem entirely, perhaps using analogy to look at the system in an entirely different way. They may even simplify the whole problem by choosing to imitate another design. Using task complexity as a framework for describing the design task allows us to better identify areas where NeuroIS may offer useful insights into the design process.

\section{Complexity in Design}

The task complexity construct has been studied extensively in the psychology literature. In the late 1980s two major surveys of the literature were published (Campbell, 1988; Wood, 1986). Because the conclusions of the two reviews were somewhat contradictory, for the next 20 years researchers who applied the construct tended to choose whichever definition was more convenient, or at least familiar. A subsequent review (Gill \& Hicks, 2006) updates these earlier reviews and concludes that five distinct classes of task complexity definition are commonly applied in the literature: three based upon sources of task complexity (lack of structure, nature of the problem space, and objective characteristics) and two related to the consequences of task complexity (experienced complexity and information processing). A latter refinement to this conceptual scheme (Gill \& Murphy, 2011) adds a sixth class, referred to as ruggedness, drawn from evolutional biology that describes the fitness of various possible end-states for a task (Kaufmann, 1993). This allows the six classes to be organized into a pleasing symmetry of three dimensions - unfamiliar, complicated, and the objectively complex (Gill \& Murphy, 2011) - as seen in Table 1. Each dimension represents a continuum of levels.

Table 1: Dimensions of Task Complexity

\begin{tabular}{|l|l|l|l|}
\hline $\begin{array}{l}\text { Unfamiliar (experienced } \\
\text { complexity): }\end{array}$ & Lack of structure & $\rightarrow$ & $\begin{array}{l}\text { Subjective experiences (e.g. dif- } \\
\text { ficulty, uncertainty, ambiguity) }\end{array}$ \\
\hline $\begin{array}{l}\text { Complicated (problem space } \\
\text { complexity): }\end{array}$ & $\begin{array}{l}\text { Nature of problem space } \\
\text { (e.g. paths, size) }\end{array}$ & $\rightarrow$ & $\begin{array}{l}\text { Information processing (e.g. cy- } \\
\text { cles, capacity) }\end{array}$ \\
\hline $\begin{array}{l}\text { Objectively Complex (real } \\
\text { world complexity): }\end{array}$ & $\begin{array}{l}\text { Objective characteristics } \\
\text { (e.g. number of ele- } \\
\text { ments, interrelation- } \\
\text { ships, dynamics) }\end{array}$ & $\rightarrow$ & $\begin{array}{l}\text { Ruggedness (e.g. number of fit- } \\
\text { ness peaks, sensitivity to small } \\
\text { change), turbulence (e.g. punctu- } \\
\text { ated equilibrium) }\end{array}$ \\
\hline
\end{tabular}

\section{Unfamiliarity (experienced complexity)}

The unfamiliarity scale is evident in design; for example, some design tasks may be repetitive and highly familiar, such as a customer service representative configuring a new PC over the phone. Such tasks are, for the most part, deemed too trivial to be of interest to IS design research (Hevner \& Chatterjee, 2010, p. 7). At the other extreme, an entirely unfamiliar task would be one for which the designer has no relevant experience, and for which uncertainty and perceived difficulty will probably be high. Here a variety of options may be open: research/learning, analysis/modeling, imitation, intuition, and so forth. On this dimension, NeuroDesign research might give us a sense of the degree to which an individual's cognitive predisposition influences how he or she chooses to approach unfamiliar design problems.

\section{Complicatedness (problem space complexity)}

The complicatedness dimension is determined by the designer's own mental models - referred to as the problem space (Newell \& Simon, 1972) - of the task. This particular form of task complexity is very close to that originally defined by Campbell (1988) and is particularly sensitive to factors such as the number of successful vs. unsuccessful paths to a particular goal, the degree to 
which decision outcomes are probabilistic, and the reversibility of decisions. For this reason, the dimension has also been referred to as path entropy (Gill \& Hicks, 2006).

\section{Objectively Complex (real world complexity)}

The objectively complex dimension of task complexity principally deals with the fitness of end states or task goals. This form of complexity is directly tied to the external environment, the "real world", because the fitness of a particular design artifact will ultimately be tied to the process of external adoption and adaptation. It is particularly important in design research because, by their very nature, nearly all significant design tasks involve identifying a suitable end state that will ultimately be embodied in the resulting design artifact. End state fitness is also the only aspect of a task that is likely to be performer-independent; both familiarity and the complicatedness of the problem space cannot be determined without reference to the performer's knowledge. Wood's (1986) objective complexity comes closest to this dimension (although it is not clear that he perceived it in these terms). His three sources of complexity - component, coordinative, and dynamic - closely parallel the sources of ruggedness in Kauffman's (1993) fitness landscape: the number of attributes in a system, the degree to which they interact to determine fitness, and the degree to which co-evolving systems exert dynamic impact on the landscape.

Ruggedness expresses the degree to which attributes of the task's paths and end state jointly determine fitness. At one extreme, fully decomposable, each attribute contributes to fitness independently. For example, a point value for each question in a test might be added to determine the final score (fitness) of a test. At the other extreme, chaotic, only the specific combination of attribute values tells you anything about the state's fitness. For example, the mapping of ingredients and preparation techniques to the tastiness (fitness) of a particular recipe may have some limited decomposability. For example, an individual may particularly like the dominant ingredient (higher fitness) or may be allergic to another (extremely low fitness). But, for the most part, it is the combination of ingredients that is the most important determinant of fitness. Furthermore, highly rugged tasks necessarily exhibit many local fitness peaks - that is essentially a mathematical property of ruggedness, as explored by Kauffman (1993).

The impact of ruggedness on the design task can be quite significant. Low ruggedness design problems can generally be decomposed and solved incrementally. For high ruggedness design tasks, on the other hand, the major design challenge is to find an appropriate intended end state to target. Most IS design tasks - even those where familiarity with the technology is high — will involve a task that is both complicated and objectively complex. This combinatorial or compositional aspect of design has yet to be rigorously explored.

\section{Neuroscience and Complexity}

Figure 3 summarizes the three complexity dimensions in terms of unfamiliarity, path, and goal. There is some evidence that these dimensions map to different regions of the brain.

\section{Lack of Structure}

Prior neuroscience research classifies design tasks as ill-structured, in that there are typically no predefined behavioral sequences for task completion, the task is open ended (it may not be obvious when the task is completed), and there may be no well-defined criteria to assess whether the task goals have been met. In an fMRI study of initial problem structuring (study phase) and solution generation or execution (performance phase), Gilbert, Zamenopoulos, Alexiou, and Johnson (2010) draw contrasts between design and more structured problem solving tasks. They find greater right dorsolateral prefrontal cortex (PFC) activity during the study phase than in the performance phase in ill-structured tasks. This result was consistent with Goel and Grafman (2000) who speculate that the right PFC is needed to generate missing information in the problem state- 
ment as well as define the task scope. This activity during the study phase is coupled with two other areas: the precuneus (which supports visual imagery) and the left frontal pole (which has been found to deal with ill-structured situations and self-generated, internal information representation).

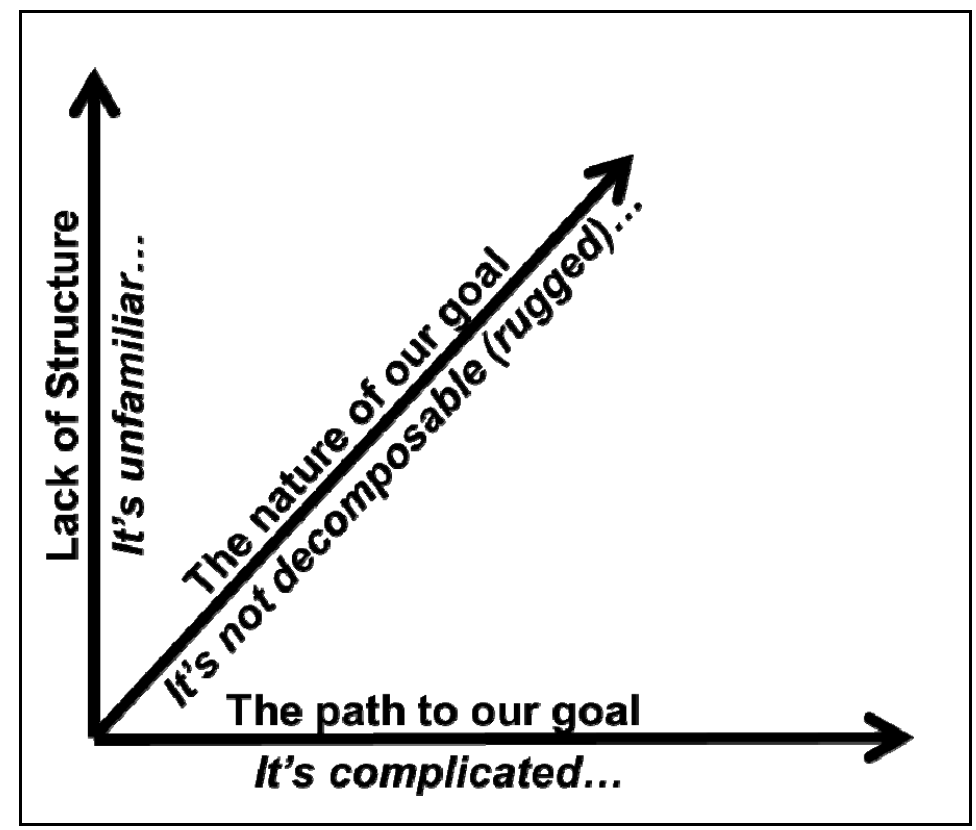

Figure 3: Complexity dimensions expressed in terms of familiarity, path and goal

\section{Utility and fitness}

Although objective complexity describes the ruggedness of the fitness landscape, the actual fitness of most design outcomes cannot be rigorously determined until well after the artifact has been put into use. For this reason, we need to estimate the likely fitness of design artifacts throughout the design process. Utility provides a mechanism - often an unconscious one - for estimating the fitness of each alternative considered (Gill, 2010; Gill \& Hevner, 2013). The study of utility also provides a bridge between two emerging economic sub disciplines: neuroeconomics (Politzer, 2008), where the study of utility is a central theme, and evolutionary economics, where our specific utility preferences are assumed to have evolved as a mechanism for maximizing our likelihood of survival (Gandolfi, Gandolfi, \& Barash, 2002). This relationship between utility and evolution is important since it highlights one of the more important potential benefits of NeuroIS design: distinguishing preferences that are hard-wired (i.e., evolved over millennia) from those that are acquired (i.e., learned from experience).

Utility is one area where neuroscience has conducted extensive studies and where commercial applications currently exist. For example, companies engaged in marketing research such as InnerScope, NeuroFocus, EmSense, and Affectiva attempt to measure the utility function of small groups of targeted consumers. The benefit of this approach is that it allows unconscious determinants of choice to be observed more reliably. Their findings add to an already large existing literature that documents the economic inconsistency of many of the choices we make (e.g., Ariely, 2008; Kahneman, 2011). 


\section{Complicatedness}

Realistic examples of tasks that are purely complicated-i.e., are familiar, have a known goal yet nevertheless involve a large problem space - are hard to come by. One particularly intriguing example of research in this area involves a well-known study of right-handed male London cab drivers (Maguire et al., 2000). The research finds that these individuals have posterior hippocampi that are significantly larger than those of other drivers. What makes this relevant to task complexity is the nature of the task and training. Taxi drivers in London must undergo extensive training, learning how to navigate between thousands of places in the city. This training is colloquially known as "doing The Knowledge" and takes about 2 years to acquire on average. To be licensed to operate, it is necessary to pass a very stringent set of police examinations (Maguire et al., 2000, p. 4398).

Since the task of driving a cab is inherently low in terms of goal selection (since the destination is provided by the passenger) and unfamiliarity is low by virtue of training, this represents one of those rare situations where the complexity of design — planning a route - seems to exist almost entirely along the complicatedness dimension. Among these drivers, the researchers find that the size of posterior hippocampi tends to grow with the length of driving experience (while that of the anterior hippocampi tends to shrink correspondingly), suggesting that the observed differences are more likely to be a function of performing the task as opposed to being a pre-existing basis for choosing the profession - which itself is interesting from a complexity preference standpoint.

\section{NeuroDesign Research Questions}

What is important to recognize is that nearly all design tasks will have task complexity from all three sources, albeit to varying degrees. One interesting question that NeuroDesign may help us answer involves the order in which the different complexity sources are addressed. For example, the pre-construction phases of a typical systems development lifecycle tends to reduce the complexity sources sequentially:

1. Unfamiliarity: Reduce uncertainty through feasibility analysis.

2. Objective Complexity: Establish a targeted end state to address the ruggedness of possible outcomes.

3. Complicatedness: Create a plan to manage the complications of actual development.

Returning to the question that introduced this section, it is very likely that the relative levels of each task complexity dimension will impact the choice of approach. It is also possible, however, that the designer's preference may exert considerable influence. It is here that NeuroDesign research may come into play.

Another important set of general questions arises when the interaction between the three task complexity dimensions are mapped against the subsequent three cognitive activities of creativity, control, and collaboration, as shown in Table 2. In each individual box, NeuroDesign could be used to address three important questions:

- To what extent can action and interpretation be localized to a specific area of the brain? Such localization could provide support for the overall construct validity of the complexity/stages framework presented earlier in Figure 2.

- To what extent do individuals exhibit a preference for different activities within each cell? Such findings would support the proposition that individual predispositions and preferences are likely to exert a strong overall influence on the design task.

- To what extent are observed preferences learned by the individual or evolved? The findings on this question would have important implications for the training and placement of 
designers, since learned preferences could likely be modified through training whereas evolved preferences would better be handled by designers whose profile of preferences is most consistent with the nature of the design tasks that they were most likely to encounter.

Table 2: Complexity Dimensions Mapped to Design Activities

\begin{tabular}{|l|l|l|l|}
\cline { 2 - 4 } & \multicolumn{1}{|c|}{ Creativity } & \multicolumn{1}{c|}{ Control } & \multicolumn{1}{c|}{ Collaboration } \\
\hline Unfamiliarity & $\begin{array}{l}\text { Imagination vs. Study: Do } \\
\text { we emphasize visualizing } \\
\text { the task in entirely differ- } \\
\text { ent ways or seek existing } \\
\text { knowledge to help us } \\
\text { perform the task? }\end{array}$ & $\begin{array}{l}\text { Intuition vs. Analysis: } \\
\text { When encountering unfa- } \\
\text { miliar choices, do we rely } \\
\text { on feelings or attempt } \\
\text { analysis? }\end{array}$ & $\begin{array}{l}\text { Collective vs. Specialized } \\
\text { Problem Solving: Are all } \\
\text { individuals presented } \\
\text { with the entire design } \\
\text { task or are elements of } \\
\text { the task assigned to spe- } \\
\text { cialists? }\end{array}$ \\
\hline Objective & $\begin{array}{l}\text { Breadth-first vs. Depth- } \\
\text { First: Do we consider } \\
\text { many possible goals be- } \\
\text { fore finalizing or do we } \\
\text { rapidly settle on a goal } \\
\text { then study its implica- } \\
\text { tions in depth? }\end{array}$ & $\begin{array}{l}\text { Transformative vs. Incre- } \\
\text { mental: Do we consider } \\
\text { solutions that are radical } \\
\text { departures from the status } \\
\text { quo or start a possible } \\
\text { solution then incremen- } \\
\text { tally refine it? }\end{array}$ & $\begin{array}{l}\text { Emergence vs. } \text { Compro- } \\
\text { mise: Do collaborative } \\
\text { designs emerge holisti- } \\
\text { cally or are they the re- } \\
\text { sult of compromise be- } \\
\text { tween the preferences of } \\
\text { participants? }\end{array}$ \\
\hline Complicatedness & $\begin{array}{l}\text { Exploratory vs. Con- } \\
\text { structed: Do we seek } \\
\text { brand new paths towards } \\
\text { our design goal or do we } \\
\text { attempt to construct paths } \\
\text { to a goal from known } \\
\text { segments? }\end{array}$ & $\begin{array}{l}\text { Plan-Driven vs. Flexible: } \\
\text { Are paths to artifact con- } \\
\text { struction planned in detail } \\
\text { or are they expected to } \\
\text { change continually as new } \\
\text { conditions and knowledge } \\
\text { arise? }\end{array}$ & $\begin{array}{l}\text { Tightly vs. } \text { Loosely Cou- } \\
\text { pled: Are subtasks on the } \\
\text { path to artifact construc- } \\
\text { tion organized to require } \\
\text { frequent communication } \\
\text { or can they be performed } \\
\text { independently? }\end{array}$ \\
\hline
\end{tabular}

Over the multiple iterations of the design Build cycle the activities of problem structuring will require expert cognitive abilities in order to address the following types of complexity challenges:

- Do designers exhibit an innate preference for purely complicated (large problem space, straightforward goals) versus purely objectively complex (ambiguous, uncertain goals, modest size problem space) problems?

- Does frequent exposure to complicated problems with straightforward goals change how a designer processes other types of problems (e.g., London cabdriver example)?

- Does working in rugged design environments (many local peaks, sharp fitness drop-offs) change how a designer processes design problems generally (e.g., structured problem solving studies)?

- Is the entrenchment phenomenon often observed in experts more of a product of exposure to past environments or is it largely innate to the individual?

A common theme of these questions involves the tradeoff between using past experience (e.g., rules learned from past designs and imitating successful designs) and actively exploring novel design combinations. This naturally leads to the next issue: what does neuroscience tell us about the relationship between the brain and creativity? 


\section{Producing Novelty - Creativity and Design}

Despite the long track record of research into creativity in a range of disciplines including psychology, sociology, organizational behavior, and information systems, no definition of creativity is widely accepted. Bringing something new into being or the imaginative composition of existing elements comprise the core qualities of creativity. More recent work has added utility as a significant mechanism and important quality (Gill \& Hevner, 2013). Monolithic, undifferentiated definitions and conceptualizations of creativity persist, failing to address the nuances evident in the stages of design presented in Table 2 . We note a similar 'inertia' in the conceptualization of creativity as found for complexity: despite commentaries on its shortcomings, Rhodes' $(1961,1987)$ models continue to guide research into creativity in a number of disciplines including IS. The tendency to conceive creativity as a single phenomenon or entity persists. Unifying the sociocognitive activities that enable creative works as a single, homogenous construct obscures the diversity of dimensions and stages identified in Table 2.

This issue is significant in more than a semantic sense: it has affected research design in the neuroscience field for a number of years, engendering confusion and the persistence of a number of 'theoretic duds' (Dietrich, 2007). The neural mechanisms underlying creativity are not well understood. Despite the sophistication of modern neurophysiological imaging technologies, the data they generate are often contradictory.

The persistence of the undifferentiated creativity construct sustains the presumption that the creativity of an individual can be studied using scales arising from performance measures such as assessment of divergent thinking and insight. 'Thinking Tasks' such as the Remote Associations Task (RAT) and the Alternative Uses Task (AUT) and other psychometric 'tests' provide empirical data. However, a recent review shows that creativity simply cannot be captured with any of the 'relatively coarse' theoretical proposals currently in use (Dietrich \& Kanso, 2010, p. 823).

Historically, creativity has been broadly categorized into three related research streams or subdomains: divergent thinking, the cognition of art and music, and insight. The literature on composition is found primarily in studies of cognition of art and music; it is even more diffuse than that on creativity. This is perhaps explained in part by the difficulty of defining an equivalent to creativity - the state or quality of being creative. The questionable coherence and viability of the "performance measures' used to date as surrogate metrics for creativity are compounded by the difficulty in articulating or defining the state or quality of compositional ability. The term connotes abilities that span intuition, innovation, analysis, synthesis, and embodiment - these are the activities that comprise what Couger, Higgins, and Mcintyre (1993) call 'imaginative recombination'; the ability to 'recruit' neural resources to produce new combinations of information.

\section{Creativity as a Design Challenge}

The role of creativity in the design process is illustrated in the NeuroDesign model (Figure 2) as impacting the generation of design candidates from the problem space to the solution space. This flow provides the locus to more fully articulate the creative activities that both guide and provide momentum for design, the constructs that undergird them, and their neural correlates. Here, design research presents an opportunity to overcome the limitations of 'universal' but ultimately context-free tests such as RAT and AUT.

The substantive and well defined processes and artifacts in design research provide contextual coherence to the creative design task at hand. Rather than being 'remote' the associations made during IS design are situationally bounded and comprehensive. Artifacts present a dynamic but cohesive frame of reference for a known problem space (Avital \& Te'eni, 2009; Hevner \& Chatterjee, 2010). To illustrate, models such as activity diagrams and class diagrams are complex design artifacts akin to blueprints. They ultimately represent the product of the Build phase but also 
provide snapshots of the creative process as they are revised. In this respect they differ significantly from the generic task representations provided by RAT and AUT. The generative capacity of these design artifacts overcomes the limitations of RAT, AUT, and similar instruments and their striving for generalizability.

Both the challenge and the opportunity here are significant, not least because the processes of decomposition and abstraction that drive the development of class diagrams and other representations of problem spaces and candidate designs during the Build phase are becoming more protracted: increasingly speed, functionality, and virtualization of IS present an ever-growing range of design choices. For example, service-oriented architectures (SOA) present multi-dimensional and multi-media solution spaces. These rapidly expanding spaces provide an increasingly dynamic environment, 'ecology' or 'press' (Rhodes, 1987) within which creativity occurs.

Class diagrams and similar artifacts are increasingly the primary 'creations' or 'compositions' of those who design and build information systems. They 'bring something new into being' by providing a medium through which the designer articulates their generative (or pre-potent) constructs in a logical model. The model is a blueprint and the precursor to an instantiation of a solution. The dynamic composition and re-composition that occurs as the model is revised shows that it is not just a 'tool' or a fully engineered artifact but an instance or snapshot of the creative and compositional process at a particular stage during design Build. The model is a 'way station' in the creative and sense making processes that mediates both design product and process.

The study of the creation and composition of design artifacts in IS presents an opportunity to understand both the dancer and the dance - how individuals address the challenges of unfamiliarity, objective complexity, and complicatedness in generating candidate designs, and how pairs, teams, and other stakeholding groups collaborate and exercise control during the evolution of those artifacts. Class diagrams and other design Build artifacts that evolve through the four stages shown in Figure 2 present 'self-contained' contextualized associations relevant to a known problem space. Rather than being 'remote' (per RAT), they have potential as a context-specific media from which to localize and articulate specific 'creativity constructs'. We believe this focus on representation of complex tasks will enable us to more coherently and consistently identify the cognitive brain functions and neural correlates that underlie 'composed' behaviors, and to explore whether the same correlates and brain functions support the inverse process of decomposition. The latter question is particularly pertinent to information systems since design research involves cycles of scoping, decomposition, analysis, synthesis, and re-generation.

\section{Neuroscience and Creativity}

The literature on the neural basis of creativity is fragmented, undermining consensus about the neural mechanisms underlying creativity. This is true for the literature on creativity as a whole and for the sub-domains of divergent thinking, cognition of art and music (composition), and insight. Contradictory and otherwise inconsistent research findings give rise to a lack of coherence and limit the progress of theoretical discussion in the field.

Creativity is viewed as a complex computational model of activities 'in' many areas of the brain (Dietrich \& Kanso, 2010; Fink, Benedek, Grabner, Staudt, \& Neubauer, 2007). However, the results from individual neurophysiological studies are often framed in terms of creativity in general. This is partly a matter of language - as discussed above -and also a matter of conceptual confusion. Conceptualizing and treating creativity as if it is a single entity fails to accommodate its complexity and infers that it comprises a limited number of fundamental processes and brain structures underlying it. Dietrich and Kanso (2010) point out that this is likely to be a fallacy, and that "it is hard to believe that creative behavior in all its manifestations - from carrying out exquisitely choreographed dance moves, to scientific discovery, constructing poems and coming up 
with ingenious ideas of what to do with a brick - engages a common set of brain areas or depends on a limited set of mental processes" (Dietrich \& Kanso, 2010, p. 845). Nevertheless, the 'fallacy' is perpetuated by the publication of results which, for instance, "... support the notion of righthemispheric superiority in creative thinking" (Mihov, Denzler, \& Förster, 2010, p. 445].
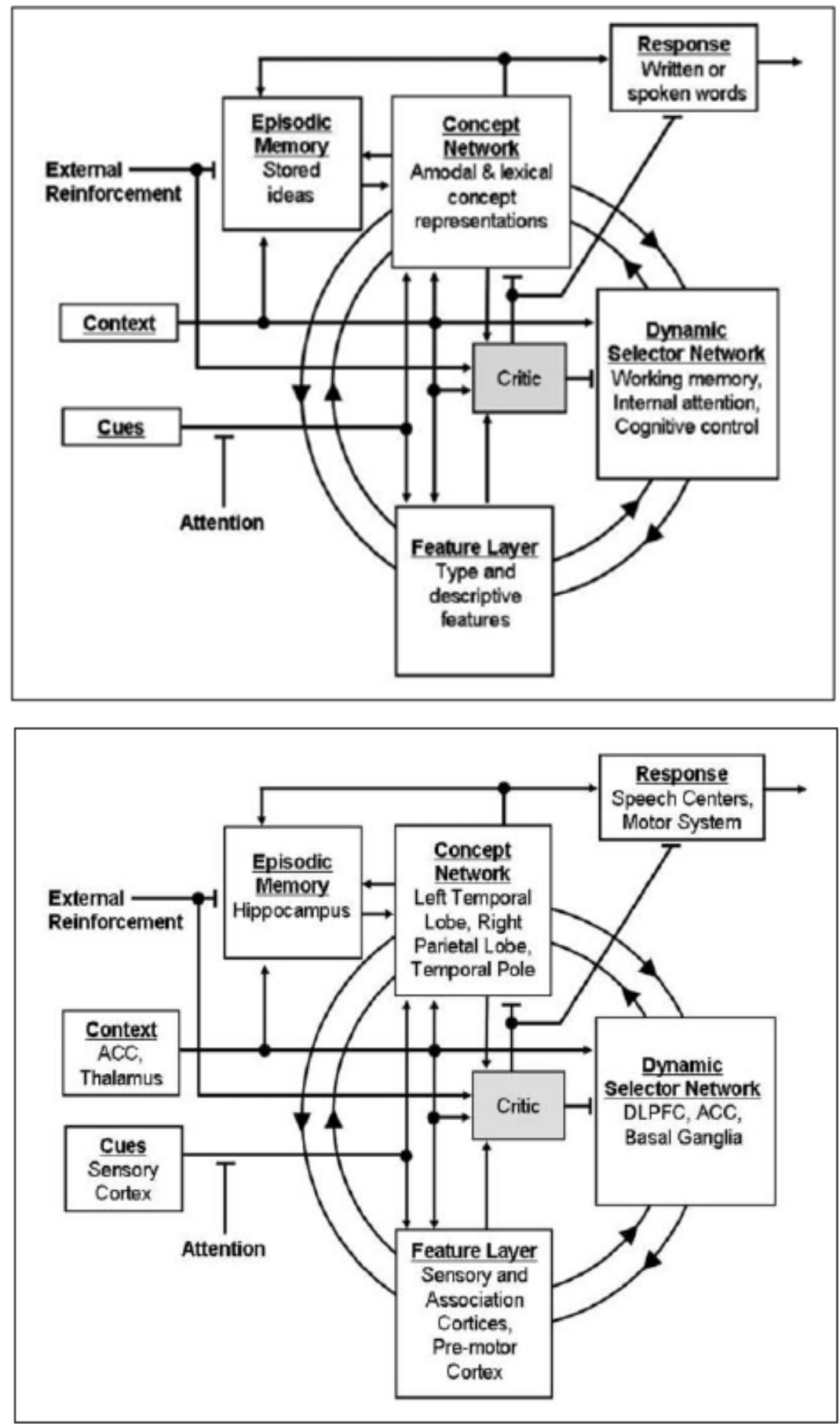

Figure 4: Mapping of Creativity to Brain Regions

(from Paulus et al., 2010) 
The neuroscience literature has been used by Paulus, Levine, Brown, Minai, \& and Doboli (2010) to propose a model that attempts to unify conflicting psychological perspectives on creativity as shown in Figure 4. Although some synthesis and structure is offered, the definitional and unit of analysis issues summarized in Table 2 remain. Is creativity a 'mysterious result of spontaneous irrational processes' or a 'planned, deliberate result of a methodical problem solving strategy' or an amalgam of both (Paulus et al., 2010)? The persistence of this question highlights the fragmentation and incoherence in studies of creativity conducted to date in the neuroscience field. Studies of creative insight by Kounios et al. (2006) support the arguments for a methodical process put forward by Paulus et al. (2010).

Insight is a significant construct in the production of novelty since it underlies both creativity and the notions of intuition and improvisation that comprise composition. Insight involves "preparing to strongly activate pre-potent candidate solutions (such as those presented as artifacts during the build phase of design) while also preparing to switch attention to non-pre-potent candidates (perhaps abstractions that 'build out' from representation by a blueprint or similar design artifact) thereby enabling retrieval of weakly activated 'solutions' characterized by remote associations among problem elements" (Howard-Jones Blakemore, Samuel, Summers, \& Claxton, 2005, p. 889).

Although clearly relevant to iterations in the build process, it has been argued that isolation of the neural correlates associated with insight undermines the ability to investigate creativity more comprehensively. Dietrich and Kanso (2010, p. 822) lament that "to most neuroscientists, the prospect of looking for creativity in the brain must seem like trying to nail jelly to the wall."

Although research on creativity in IS has a long history (e.g., Avital \& Te'eni, 2009; Bilalić, Mcleod, \& Gobet, 2008; Csikszentmihalyi, 1996; Dean, Hender, Rogers, \& Santanen, 2006; Santanen, Briggs, \& de Vreede, 2004; Satzinger, Garfield, \& Nagasunduram, 1999) studies have been limited both in number and in the range of theoretic frameworks and research methods applied. In a recent review, Seidel et al. (2010) show that the majority of IS studies on creativity analyze the impact of IS use on the potential of individuals and groups to 'compose' or generate creative outcomes - but typically focusing on the artifact or product as causal 'independent variables'. The emphasis is clearly on generative 'fit' - the attributes of the artifact or system - rather than their generative capacity (Avital \& Te'eni, 2009). Studies also persistently characterize IT as a 'tool', an "engineered artifact, expected to do what its designers intend it to do" (Orlikowski \& Iacono, 2001, p. 123). This rather narrow epistemological perspective gives rise to a prevalence of variance theories: this puts the 'cart before the horse' (Seidel et al., 2010, p. 234).

Variance theories embody the IT artifact, masking the dynamics of the (socio-cognitive) activities underlying its complexity, creation, composition, and later use and evaluation as shown in Figure 2. The limitation of variance theories is compounded by the conceptualization of the IT artifact as enabling the creative process and an emphasis on the outcome or product of the process rather than the context or environment (press) in which the process occurs. Although there has been some research into specific application contexts or 'presses' in studies of creative artists such as musicians (Eaglestone, Ford, Brown, \& Moore, 2007) they are few and far between and do not address the process dynamics that characterize creativity.

Research on composition in IS is even more sparse. Hungerford, Hevner, and \& Collins (2004) report the evolution of a shared mental model among developers when searching for defects in design diagrams. Four distinct techniques (or what we might call compositional styles or choreographies) are found, the most effective of which was characterized by 'fast-switching' between the design artifacts into which defects had been seeded. The focus on defects as a means to investigate composition has further potential. For example, Bechtereva and Nagornova (2007) use error detection as the primary construct in their neurophysiological study. 


\section{NeuroDesign Research Questions}

Dietrich \& Kanso (2010, p. 824) argue that “...only by systematically reviewing the evidence for different conceptions of creativity can the temptation to continue to appraise creativity as a single, simple mental process or brain region be overcome." The artifacts produced during design Build present an opportunity to deepen our understanding of the creativity and composition processes and, perhaps, move toward some theoretic cohesion. The artifacts themselves embody both the generative capacity and the products of the creative process and as such provide instantiations of candidate designs and problem solutions that are much richer and potent than RAT and AUT.

Design artifacts such as class diagrams provide a rich medium that provide the basis for preclinical experiments to elicit specific constructs that individuals use as they bring these artifacts into being. Prior work in this area using cognitive mapping (Brooks, Davis, \& Lycett, 2005), verbal protocol analysis (Hutchins, 1995), and other techniques has successfully articulated shared mental models. Careful attention to the design of these pre-clinical experiments, perhaps using supplementary feedback techniques (e.g., C. Davis \& Hufnagel, 2007) will enable the constructs undergirding the creation of these rich representational media to be validated prior to any physiological investigation of their neural correlates.

Exploring the evolution of artifacts such as class diagrams during the build process gives rise to two distinct but complementary research opportunities. First, the constructs and their interrelations that comprise the shared mental model of the class diagram or other artifact could be used as the basis for process tracing using EEG, fMRI, or other imaging techniques to identify the neural correlates underlying creativity. The four design Build stages in Figure 2 provide a sound basis for the use of specific context and cues, with specific concept representations and descriptive features. These are central to Paulus et al.'s (2010) mapping of creativity to brain regions as seen in Figure 4. Process tracing is attractive since it can accommodate all the observable brain activity during a context- or problem-specific task, such as identification of an intersection entity to break a many-to-many relationship in an entity relationship diagram or a similar task to refine a class diagram. Process tracing is often used to complement comparative case study methods. Thus, scarce neuroimaging resources could provide the basis for triangulation of data from observational, interview, and other studies involving a larger sample size.

Second, and perhaps more importantly, such pre-clinical experiments would articulate the frame of reference or mental model used by designers during the Build phase. This would provide the basis for the development of a nomological network for complexity, creativity, and composition. The potential contribution here is substantial: in addition to consolidating the validity of existing and newly elicited constructs and the relationships between them as outlined in Table 2, this would broaden the focus of research into creativity, the centripetal force driving the four stage design Build cycle and knowledge generation and 'growth' modeled in Figure 2.This, in turn, would provide insight into design research cycles substantially beyond the bounds of 'familiar', routine design to explore the realms of design improvement, invention, and exaptation rather than limiting empirical work to the evaluation of a priori constructs drawn from prior studies dependent largely on variance theories (Greenberg \& Dickelman, 2000).

Additional research questions surrounding creativity might include:

- Why do some designers gravitate towards imitation while others gravitate towards exploration?

- Why do some designers prefer to incrementally add to the existing problem space whereas others prefer to restructure or start from scratch? 
Hevner, Davis, Collins, \& Gill

\section{Managing Refinement - Control and Design}

A student once asked Linus Pauling, "Dr. Pauling, how does one go about having good ideas?" He replied, "You have lots of ideas and throw away the bad ones" (Csikszentmihalyi, 1996, p. 116). Effective design innovation requires more than just the generation of many creative ideas. Many creative individuals waste time, energy, and resources chasing infeasible and unprofitable hunches into blind alleys. Successful innovation also requires the intellectual control to refine creative thinking into practical solutions. Such control is dependent on the cognitive skills of reason and judgment that can be investigated via neuroscience.

The development of effective and efficient IT system designs provides many examples of the need for controls. Mills (1983), in his early ground-breaking work on chief programmer teams, emphasized that one mind must have intellectual control of the software design for a project to move forward and be successful. He focused on the human mind's ability to use abstraction to build hierarchical mental models of the evolving system. The current enthusiasm for agile development methods appears to move away from controlled, disciplined processes. However, recent research grounded in control theory (Ouchi, 1979) has shown that agile methods employ a wide range of controls; termed emergent outcome controls (Harris, Collins, \& Hevner, 2009). Two examples of emergent outcome controls are scope boundaries in which a development task is bounded by a small, well-defined functional requirement or time limit and ongoing feedback at regular time intervals to rapidly incorporate corrections and improvements.

\section{Control as a Design Challenge}

In essence, maintaining intellectual control of the evolving Build activities in design research results in the reduction of uncertainty. Drawing from our ideas of problem structuring and complexity, we identify two types of uncertainty:

- Reducible Uncertainty - The problem can be decomposed into sub-problems that can be addressed independently via control techniques of learning, planning, abstraction, solution specification, and composition of solutions.

- Irreducible Uncertainty - The problem has no clear decomposition and must be solved as a whole via control techniques like scenario generation and risk management.

A major challenge in problem structuring is differentiating between these two situations and then applying the most effective controls in order to refine the selected design candidates to use artifacts as shown in Figure 2. The process of design refinement asks the following key Build questions:

- Is the design feasible? - Can the proposed design be implemented and does the proposed design meet the requirements? Building feasibility artifacts moves designs across the unknown/known partition.

- Does the design have value? - Does the design offer benefits unmatched by competing candidate designs? Here the objective becomes to establish an ordinal valuation that can be used to rank candidate designs.

- How can the design be most effectively represented? - How can we best communicate the intricacies of the design to collaborators, implementers (e.g., architects, programmers), and other stakeholders?

- How best to construct the actual use artifacts? How do we guide the construction of the use artifact? As examples, a blueprint is a construction artifact that serves to guide the physical construction of a house; source code is a construction artifact that serves to generate the programs that are distributed to users. 


\section{Neuroscience and Control}

The above questions are answered by the skilled use of the human cognitive facilities of reason and judgment.

\section{Reason}

Human reason reflects thinking in which plans are made, hypotheses are formed, and conclusions are drawn on the basis of evidence in the form of data, past experience, or knowledge (Carson, 2010). While creativity often calls for divergent thinking to break out of mindsets; reason calls for convergent thinking to refine ideas into practical artifacts and actions. Moving design ideas from 'blue sky' to artifact instantiations requires goal setting and a plan to answer the Build questions above.

Neuroscience studies have located human reasoning centers in the left dorsolateral prefrontal cortex (DLPFC) which is the area that controls planning, reasoning, and decision making. The right DLPFC featuring more holistic insight comes into play when problems involve larger amounts of irreducible uncertainty (Charron \& Koechline, 2010; Howard-Jones et al., 2005). Other areas that activate during reasoning and problem solving are the brain centers (e.g., angular gyrus, supramarginal gyrus, Wernicke's area) that integrate information from the senses and transmit this information to the DLPFC. Another factor critical to effective cognitive reasoning is the increased presence of arousal neurotransmitters, such as glutamate, dopamine, and norepinephrine. Such arousal is associated with increased high frequency/low amplitude beta wave activity in the DLPFC (Parasuraman, Warm, \& See, 1998).

\section{Judgment}

Closely related to reason is the human cognitive facility to judge, or evaluate, ideas at various design stages of the Build process. The goal of judgment is to predict the future; to predict which candidate designs will be better than others. Without the ability to narrow the field (i.e., design space) it would be impossible to refine many good ideas down to one 'satisfactory' design artifact. This is a very tricky area of human cognition since it involves self-criticism, self-esteem, and motivation. However, studies have shown that humans are capable of making effective and rapid judgments based on first impressions (e.g., Ambady \& Rosenthal, 1993). Beyond first impressions, design evaluations in design research depend on the rigorous definition of utility functions that estimate the values of candidate designs in order to facilitate the ranking of alternatives (Gill \& Hevner, 2013).

During the judgment activities of design, the brain is characterized by active evaluation, focused attention, and impersonality (Carson, 2010). Similarly to the reasoning brain, the judging brain shows strong activity in the left DLPFC as decision-making and analytic activities dominate (Srinivasan, 2007). Additional activities are seen in the orbitofrontal cortex (OFC) and anterior cingulate cortex (ACC) which are related to the judgment of positive and negative impacts of events. As noted in the complexity section, emerging research in neuroeconomics also brings into play the nucleus accumbens (the 'reward' center of the brain) to better understand how we cognitively evaluate alternatives and make decisions that make us feel good about ourselves (Sanfey, Loewenstein, Mcclure, \& Cohen, 2006).

\section{NeuroDesign Research Questions}

There are a number of research challenges as we attempt to better understand the relationships among complexity, creativity, and control to improve design processes. Some examples include:

- Planning effective design processes: Within the management literature, it has been observed that many entrepreneurs exhibit a distinctly different problem-solving approach 
than that used by the traditional manager (Sarasvathy, 2003). Framed in task complexity terms, managers tend to reduce unfamiliarity (e.g., through analysis, model building), select a goal, and then plan (to deal with complicatedness). Entrepreneurs, described as effectuators, tend to reduce all three sources of task complexity in parallel through an iterative process and set of controls not unlike that used in agile methods. Determining the relative contribution of brain-driven reasoning and judging activities and the task complexity dimensions outlined in Table 2 would be useful in helping us to better understand the choices we make and, perhaps, improve them.

- Understanding the potential impact of obstacles on design: A recent series of psychological experiments have suggested that introducing obstacles and additional uncertainties in a task can actually improve the quality of problem solutions (Marguc, Förster, \& Van Kleef, 2011). From a design complexity perspective, this might be viewed as adding constraints that increase complicatedness to force a broader consideration of possible goals, since the obstacles have the effect of making the most obvious or entrenched goals harder to reach. This perhaps moves some brain activities from the left DLPFC (analytic) to the right DLPFC (insight) to deal with a more complex and holistic problem. Understanding how such obstacles change problem solving processes in the brain might offer clues as to how to make strategic use of obstacles to produce more innovative designs.

- Understanding the impact of interference by competing designs: An interesting pair of experiments has been conducted demonstrating the Einstellung effect, whereby early solutions that are good prevent considerations that are better (Bilalić et al., 2008). The implications for IT systems design are self-evident. A better understanding of how such processes operate could be particularly valuable in design situations where ruggedness is high, since these circumstances necessarily produce many local peaks that are likely to be far less fit than the highest peaks. How do we provide controls in the design process to continue the search beyond local maxima? This will require a search process that effectively iterates between divergent thinking (creativity) and convergent thinking (control).

Briefly, a few additional research questions involving control are:

- Why do some designers prefer a design-then-build philosophy (e.g., waterfall) versus a design-as-you-build philosophy (agile methods)?

- Why do some designers prefer decentralized control (e.g., component-based systems) while others seek more centralized design (e.g., integrated systems)?

\section{Achieving Consensus - Collaboration and Design}

Design research projects are performed by teams with diverse skill sets and an equally diverse range of stakeholders. Producing a satisfactory design artifact for release into an application context brings the cognitive challenges of collaboration among members of the research team and effective communication to and from stakeholder audiences into sharp relief. The collaborative aspect of NeuroDesign is at the intersection of social cognitive neuroscience and collaborative design research based on distributed cognition. In collaborative design tasks the goal is collaborative emergence of a design based on contributions from the design team. In a well-functioning and successful design team, individuals' "talent, energy, and skills are integrated into a team, and this collective capacity to innovate becomes greater than the sum of individual contributions" (Chen, 2007, p. 239). The research tools of neuroscience provide an opportunity to better investigate the collaborative design work of teams and how best to form them. 


\section{Collaboration as a Design Challenge}

A particular challenge of this kind of NeuroDesign study is that both the cognitive activities of individuals in a team as well as external manifestations of collaboration (e.g., discussions, design representations) must be measured and combined to understand the phenomenon. For example, neuroscience research on the neural correlates of specific kinds of complex tasks like problem structuring can assist in investigations of the principle of problem identification in design research: developing technology-based solutions to business problems that are relevant and important (Hevner et al., 2004). In particular, as we study collaborative design, this knowledge about brain activity related to specific Build processes like problem structuring will enable detailed measurement of when individuals are working on the design process, and if and when those cognitions are shared.

Social cognitive neuroscience is congruent with distributed cognition research, since this more traditional cognitive science research area investigates knowledge representation both inside the heads of the individual and in the world, and the propagation of knowledge between individuals and artifacts (Gregor \& Hevner, 2013). Flor and Hutchins (1991) propose that cognition should be looked at as a distributed phenomenon - how knowledge is represented both internally (inside one's head) and in the world (environment, culture, social interactions); the transmission of knowledge between different individuals as artifacts; and the transformations through which external structures go when acted on by individuals and artifacts. Inclusion of these individual and shared processes in our NeuroDesign model (Figure 2) focuses our research efforts on increasing our understanding of how intelligence is exhibited at the systems level as well as at individual cognitive levels. For example, Flor and Hutchins (1991) study how two programmers coordinate the task of software maintenance, utilizing distributed cognition to explain their collaborative behavior.

Nardi (1996) notes that distributed cognition is concerned with representation - both inside and outside the mind. Because of this focus on both internal and external representations, much attention is paid to studying these representations. For example, in a study of sailors navigating a ship, Hutchins (1995) identifies a number of principles: cognition is mediated by tools; the critical role of the tool mediation in cognition means that cognition is rooted in the artificial; and cognition is a social affair that involves delicate variations and shades of communication learning and interpersonal interacts. Nardi (1996), drawing upon Hutchins's work, stresses the importance of "functional systems," or systems that are made up of a person's or a group's interaction with the tool. In our NeuroDesign model, the 'tool' is the medium for the articulation and sharing of prepotent candidate designs, mediating both creative and collaborative processes. Thus the model (Figure 2) accommodates the social system as an important unit of analysis. The compositional interdependencies of individual, tool, and artifacts; social and communication interactions; and the work environment that constitute the complex, interacting systems (Greenberg \& Dickelman, 2000) in which design Build takes place are brought into focus.

Understanding how a team collaborates on the design task and comes to consensus thus becomes a task of measuring what is observable and matching the internal and external evidence to understand the team's work. Brain activities of individual members of a team can be classified by prior neuroscience research to provide insight into the nature of task-related thought and more sociallyfocused thinking. Recordings of discussions between team members, their tool usage, and any external representations like models can be analyzed for evidence of sharing, disagreements, or conflict as the team moves to consensus on the design. 
Hevner, Davis, Collins, \& Gill

\section{Neuroscience and Collaboration}

Some social neuroscience studies investigate whether forming teams based on understanding differences in brain activity improves performance. For example Woolley et al. (2007) note that within individuals "different brain systems must work together", and posit that with teams it is important to examine "the ways in which the brain systems in different members" heads function together" (p. 102). They looked at matched and mis-matched pairs (based on matches between team members with abilities needed for the task) working on a novel problem solving task that required both spatial and navigation abilities, and they found a benefit from fit between task and team member abilities, as well as higher levels of collaboration. The highest performance was by teams where individuals were assigned task roles congruent with their abilities, but was equaled by teams with incongruent role assignments who had members with the needed abilities (functional diversity) and high levels of collaboration. They conclude that:

"the results are compatible with a view of brain evolution that stresses the role of social interactions. Different brain systems may have evolved not only to work together within a single head, but also to work together between heads - that is, so that different systems are not only "plug compatible" within a single brain, but also across brains." (Woolley et al., 2007, p. 103)

In addition, social cognitive neuroscience investigates the biological correlates of a wide range of social processes, such as those needed for collaborative design. This research finds a clear division between the neural correlates of tasks that are internally-focused (attention to the mental, emotional, and experiential characteristics of the self or perception of those in others) and those that are externally-focused (attention to the physical and visual characteristics of others, oneself, or interactions between the self and others). The lateral frontotemporoparietal network is activated by external focus, and the medial frontoparietal network is activated by internal focus. While collaborative design requires external focus on external representations and the design artifact, it may also involve internally-focused cognitive activity, such as trust in others in a design team (Lieberman, 2007).

Figure 5 is an example of how a cognitive approach to the collaborative aspects of design can be employed to investigate the design principles of problem identification and representation. Some of the relationships are conceptualized as iterative, since what happens in collaboration is likely to influence subsequent cognitions by individuals, which then, in turn, impacts the collaboration. Such research will require a combination of research methods, including neuroscience techniques like fMRI to measure brain activity; task analysis to identify all needed knowledge, skills, and abilities; measurement of individual knowledge, skills, and abilities; recording and analysis of team interactions; collection and evaluation of all external representations of the design (e.g., on whiteboards and paper); logging of use of tools; and evaluation of design outcomes. Such multiple methods enable a view of the entire "functional system" of collaborative design.

\section{NeuroDesign Research Questions}

The central research challenge regarding collaborative design is to understand how to assemble and support design teams that interact effectively to produce great designs. To meet this challenge we must study how individuals work alone and together on all design processes, as they solve complex problems in creative ways with appropriate controls. Such research requires methods that reveal individual cognitions (e.g., neuroscience); the knowledge, skills and abilities that each individual brings to the team (e.g., survey measures); team interactions and representations (e.g., video and audio recordings of interactions, collection of models and other external representations); as well as design outcomes (e.g., design artifacts). This multi-level and multi-method approach can leverage neuroscience knowledge to open up the black box on individual cognition 
along with the more traditional ways of investigating collaboration to draw a more complete picture of collaborative design.

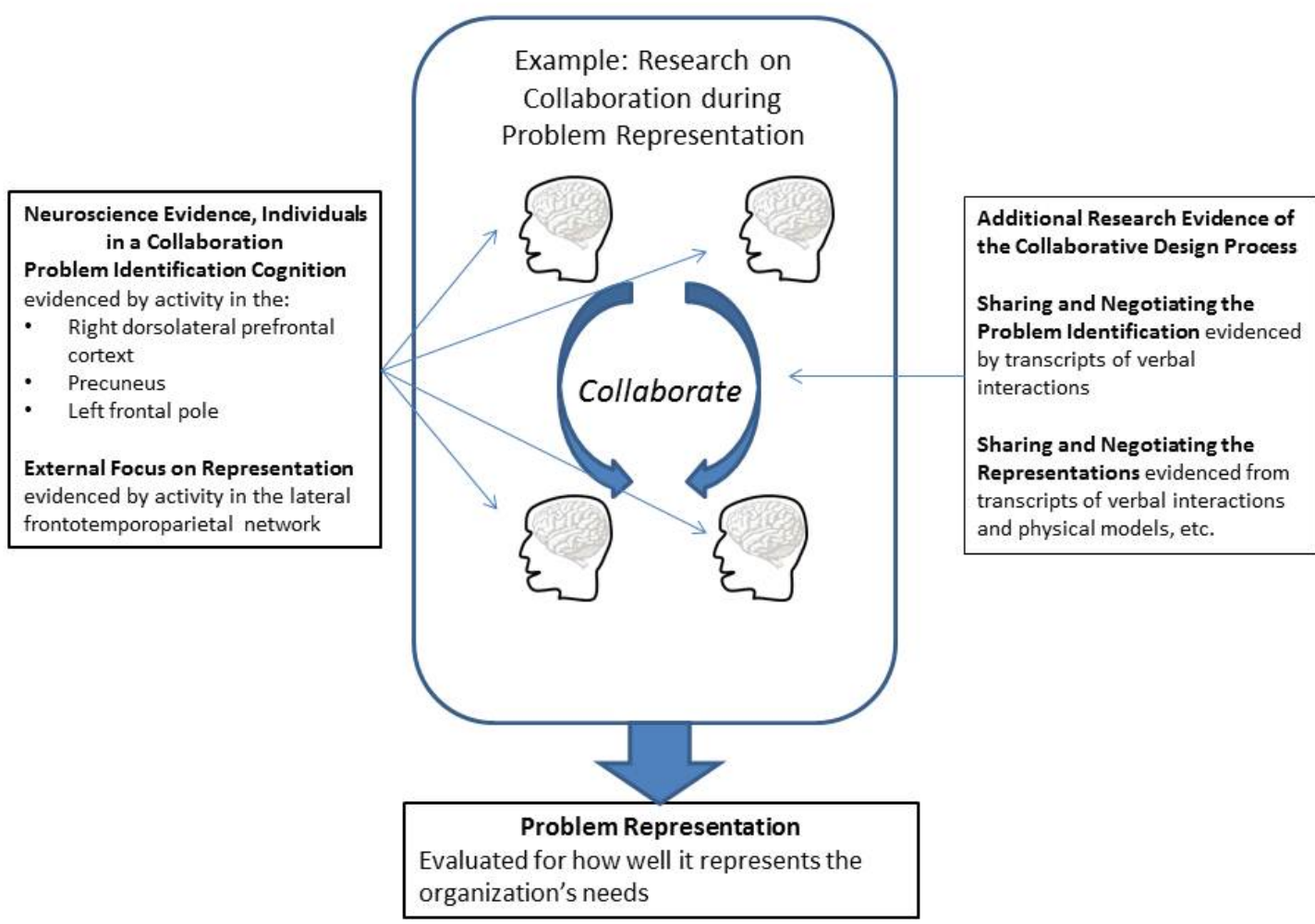

Figure 5: The Collaborative Design Process

Some research may focus on the contrasts between individual and collaborative design settings:

- Why do some designers prefer collaborative design (e.g., design teams, pair programming) whereas others seem to prefer working alone?

While other research may investigate design team formation or processes:

- For design tasks, what team member characteristics create the best combinations to achieve functional diversity?

- How does tight collaboration impact the choices made by designers (e.g., does the need to move more of the design elements into the symbolic problem space in order to promote sharing change the way our brains are activated during the design process?)

- Can effective knowledge sharing during design interactions overcome lack of congruency between team members in their knowledge, skills and abilities? (Weedman, 2008).

\section{The Exciting Potential of IS NeuroDesign Research}

The potential relationship between cognitive neuroscience and IS design research could be one of great synergy. Cognitive neuroscience techniques such as fMRI provide considerable face validity in their ability to relate specific cognitive activities to specific regions of the brain. However, 
we face at least three significant challenges in the development of a NeuroDesign research program.

1. Prioritizing the myriad cognitive activities in which we engage for study. Humans exhibit so many different types of processes related to design thinking that it could decades - if not centuries - before we acquire full understanding of all design activities that involve conscious or unconscious thinking. Isolating and prioritizing cognitive activities for study is difficult.

2. Addressing the problem of experimental context. The most sophisticated approaches to studying the brain in action involve such intrusive experimental settings (e.g., an MRI tube) that the generalizability of any experimental results must rightfully be questioned. The narrower the cognitive task being investigated, the more likely it is that researchers will be able to devise experimental settings that minimize observer impact on the subject.

3. Justifying the value of the experimental findings. While it may seem self-evident to researchers that understanding is a worthy goal in and of itself, the same sense of value may not be present on those who pay the price of research. The question of how better understanding the brain operation ultimately improves our abilities must therefore be a practical concern to all researchers seeking to justify their findings and fundings.

NeuroDesign research conducted using the framework that we have presented offers benefits with respect to all three challenges. The Figure 2 model breaks down the design problem into more primitive task types and provides a justification - based upon observed behaviors - that they can be important elements of the design process. This approach also yields tasks that are more readily studied under experimental conditions. Perhaps most importantly, in a world where routine tasks are frequently offshored, the design process remains a critical source of competitive advantage to those countries most heavily invested in neuroscience research. Given that many design behaviors commonly observed - such as entrenchment - seem likely to inhibit design quality, better understanding the sources of these behaviors could provide an important means of sustaining existing advantage.

The benefits of collaboration between design research and cognitive neuroscience work in the opposite direction, as well. As shown in Figure 2, real-world design is dependent upon human facilities in areas such as creativity, control, and collaboration that have a large non-symbolic component. Broken down further, complexity-driven constructs such as utility, ambiguity, and uncertainty represent feelings, as do constructs such as intuition and empathy which seem central to how we choose alternatives and evaluate designs. Being non-symbolic, we need to be skeptical of explanations offered by designers. As a practical matter, this means that models (such as that presented in Figure 2) need to be validated lest they be treated as mere speculation.

We posit that NeuroDesign studies represent a mechanism for verifying models that have been induced from behaviors. To the extent that we observe unique or characteristic pathways for distinct processes in our models, we have another basis for arguing for their validity. Where expected activities prove to be indistinguishable, it suggests that our existing models need to be reconsidered. In a very real sense, we can view this model building and validation process as itself being an iterative design process. What cognitive neuroscience offers us is a basis for trimming and/or expanding our model 'designs'. Without it, design research is likely to evolve mainly through building speculative models on top of other speculative models, a process that is more likely to be driven by fad than by a process of rigorous scientific verification and systematic accumulation of knowledge.

In summary, we see advancements in cognitive neuroscience and IS design research as being strongly supportive of each other. If IS design researchers can feed neuroscience researchers in- 
teresting and important tasks to study, the neuroscience field as a whole will benefit from the insights. If neuroscience provides us with interesting observations in response, we can tune - or completely restructure, if necessary - our models of the cognitive mechanisms through which IS design takes place. As participants in design research, our job is to make the questions we impose so compelling to the neuroscience community that we move to the head of the queue.

\section{Role of Design Science and NeurolS within Informing Science}

Although the present paper specifically focuses on the potential application of neuroscience to information systems design, it is equally applicable to the broader informing science transdiscipline. Indeed, since its very inception (i.e., Cohen, 1999; Gill \& Bhattacherjee, 2007), the study informing science has been presented in terms of three layers:

1. A design layer: The layer at which new informing systems architectures are designed.

2. A construction layer: The layer at which informing system instances are created according to templates developed in the architecture layer.

3. An instance layer: The layer at which individual informing systems operate.

The informing science transdiscipline emerged to encourage the holistic study of all three layers. With relatively few exceptions (e.g., Kuechler \&Vaishnavi, 2011), however, the vast majority of empirical research in the field has focused on instance-level studies. The potential applicability of research questions such as the ones proposed in the present paper to informing science should be self-evident. Thus, the paper should be viewed as encouraging further research into the allimportant design layer. Moreover, by incorporating the collaborative and social aspects of design into the proposed framework, the issues presented here may well have applicability to informing systems that evolve - such as social networks - as well as systems that begin with a clear design.

\section{Conclusions}

The application of neuroscience to design and design science research, particularly as it applies to IS, is in its infancy but offers significant future prospects. Today's state of the art in NeuroIS is focused on the evaluation of design. Even now, biometric tools are being applied commercially in marketing research to evaluate new product designs. As experience with neuroscience research grows, these may be applied to the more objectively complex and complicated Build problems that we frequently encounter in IS design contexts, in other words, NeuroDesign research. Our principal contribution in this essay is a formal conceptual model of the design process and the human cognitive activities that interact in formative ways in the process to deal with the challenges of complexity, creativity, control, and collaboration.

The exciting prospects of NeuroDesign come from the range of design activities to which they could, in theory, be applied. Determining the socio-cognitive processes involved in resolving goal ambiguity (objective complexity), generating novelty (creativity), managing the overall process (control), and integrating the work of many (collaboration) should help us better understand inconsistencies to which our reasoning architecture is vulnerable and the degree to which elements of that architecture are physiologically fixed versus being learned. Such understanding, in turn, can be applied to a diverse set of questions that include: deciding how (and who) we should train for different types of design tasks, recognizing and avoiding entrenchment in design processes, and establishing environments that encourage high levels of creativity and fruitful collaboration. Improving such capabilities is particularly critical for highly developed economies, such as the U.S. and Western Europe, where non-design IT activities are frequently being offshored to countries where they can be performed less 'expensively.' 
Hevner, Davis, Collins, \& Gill

Finally, it is becoming clear that brain science has become a major research priority for the scientific community, with recent proposals directing billions of dollars towards this effort in both the U.S. and Europe. The potential flood of resources has raised concerns, however. Past research has been very successful in producing huge quantities of neuroscientific data. It has been far less successful in translating that data into understanding. A recent article in The New Yorker described the situation as follows:

"Sometimes people collect the data before they are able to develop good theories, but the best experiments are often ones that help scientists sift through competing theories. Unfortunately, in two preliminary proposals in the scientific journals (Neuron and Science), there has been relatively little discussion of what specific hypotheses will be tested, or how, with just a few words written so far about how to interpret the 'data deluge' that is to come." (Marcus, 2013)

In this paper, we have endeavored to propose and justify a set of interesting questions - questions that readily translate themselves into testable hypotheses, such as "Does the entrenchment that occurs in the design process manifest itself in distinctive patterns of brain activity?" or "Can individual preferences for imitation versus exploration in design be distinguished using fMRI data?", and so forth. Design as a critical source of competitive advantage makes these important questions; ones that deserve a prominent place at the table of future brain research. It is our firm belief that the research areas that pave the way for future investigations by building a set of questions that can, and should, be answered by neuroscience will play a significant role in the advancement of our understanding of the brain. If these questions can be the ones posed by NeuroIS researchers, then our own field will benefit immeasurably from this research as well.

\section{References}

Ambady, A., \& Rosenthal, R. (1993). Half a minute: Predicting teacher evaluations from thin slices of nonverbal behavior and physical attractiveness. Journal of Personality and Social Psychology, 64, 431441.

Ariely, D. (2008). Predictably irrational. Harper Collins, New York, NY.

Avital, M., \& Te'eni, D. (2009). From generative fit to generative capacity: Exploring an emerging dimension of information systems design and task performance. Information Systems Journal, 19(4), 345367.

Baskerville, R. (2008). What design science is not. European Journal of Information Systems, 17(5), 441443.

Bechtereva, N., \& Nagornova, Z. V. (2007). Changes in EEG coherence during tests for nonverbal (figurative) creativity. Human Physiology, 33(5), 515-523

Bilalić, M., Mcleod P. \& Gobet, F. (2008). Why good thoughts block better ones: The mechanism of the pernicious Einstellung (set) effect. Cognition 108, 652-661.

Brooks, L., Davis, C., \& Lycett, M. (2005). Organization and information systems: Investigating their dynamic complexities using repertory grids and cognitive mapping. International Journal of Technology and Human Interaction, 1(4), 39-57.

Browne, G., \& Pitts, M. (2004). Stopping rule use during information search in design problems. Organizational Behavior and Human Decision Processes, 95, 208-224.

Campbell, D. J. (1988). Task complexity: A review and analysis. Academy of Management Review, 13(1), 40-52.

Carson, S. (2010). Your creative brain: Seven steps to maximize imagination, productivity, and innovation in your life, San Francisco, CA: Jossey-Bass. 
Charron, S., \& Koechline, E. (2010). Divided representation of concurrent goals in the human frontal lobes. Science, 328, 360-363.

Chen, M.H. (2007). Entrepreneurial leadership and new ventures: Creativity in entrepreneurial teams. Creativity and Innovation Management, 16(3), 239-249.

Cohen, E. (1999). Reconceptualizing information systems as a field of the transdiscipline informing science: From ugly duckling to swan. Journal of Computing and Information Technology, 7(3), 213-219.

Couger, J., Higgins, L., \& Mcintyre, S. (1993). (Un)Structured creativity in information systems organizations. MIS Quarterly, 17(4), 375-397.

Cross, N. (2001). Design/science/research: Developing a discipline. Fifth Asian Design Conference: International Symposium of Design Science, South Korea.

Csikszentmihalyi, M. (1996). Creativity: Flow and the psychology of discovery and invention, New York, NY: Harper-Collins Publishers.

Davis, F. (1989). Perceived usefulness, perceived ease of use, and user acceptance of information technology. MIS Quarterly, 13, 319-339.

Davis, C., \& Hufnagel, E. (2007). Through the eyes of experts: A socio-cognitive perspective on the automation of fingerprint work. MIS Quarterly, 31(4), 681-703.

Dean, D., Hender, J., Rogers, T., \& Santanen, E. (2006). Identifying quality, novel and creative ideas: Constructs and scales for idea evaluation. Journal of the Association for Information Systems, 7(10), 646698.

Dietrich, A. (2004). The cognitive neuroscience of creativity. Psychonomic Bulletin and Review, 11(6), 1011-1026.

Dietrich, A. (2007). Who's afraid of a cognitive neuroscience of creativity? Methods, 42, 22-27.

Dietrich, A.,\& Kanso, R. (2010). A review of EEG, ERP, and neuroimaging studies of creativity and insight. Psychological Bulletin, 136(5), 822-848.

Dimoka, A. (2010). What does the brain tell us about trust and distrust? Evidence from a functional neuroimaging study. MIS Quarterly, 34(2), 373-396.

Dimoka, A., Bagozzi, R. P., Banker, R. D., Brynjolfsson, E., Davis, F. D., Gupta, A., \& Riedl, R. (2009). NeuroIS: Hype or hope? Proceedings of the International Conference on Information Systems, 1-10.

Dimoka, A., \& Davis, F. (2008). Where does TAM reside in the brain? The neural mechanisms underlying technology adoption. Proceedings of the International Conference on Information Systems, 1-18.

Dimoka, A., Pavlou, P., \& Davis, F. (2011). NeuroIS: The potential of cognitive neuroscience for information systems research. Information Systems Research, 22(4), 687-702.

Eaglestone, B., Ford, N., Brown, G., \& Moore, A. (2007). Information systems and creativity: An empirical study. Journal of Documentation, 63(4), 443-464.

Ethiraj, S., Levinthal, D., \& Roy, R. (2008). The dual role of modularity: Innovation and imitation. Management Science, 54(5), 939.

Fink, A., Benedek, M., Grabner, R., Staudt, B., \& Neubauer, A. (2007). Creativity meets neuroscience: experimental tasks for the neuroscience study of creative thinking. Methods, 42, 68-76.

Flor, N., \& Hutchins, E. (1991). Analyzing distributed cognition in software teams: A case study of team programming during perfective software maintenance. In J. Koenemann-Belleveau et al. (Eds.), Proceedings of the fourth annual workshop on empirical studies of programmers, Norwood, NJ: Ablex Publishing, 36-59.

Gandolfi, A. E., Gandolfi, A. S., \& Barash, D. (2002). Economics as an evolutionary science: From utility to fitness. New Brunswick, NJ: Transaction Publishers. 
Hevner, Davis, Collins, \& Gill

Gilbert, S., Zamenopoulos, T., Alexiou, K., \& Johnson, J. (2010). Involvement of right dorsolateral prefrontal cortex in ill-structured design cognition: An fMRI study. Brain Research, 1312, 79-88.

Gill, T. G. (2010). Informing business: Research and education on a rugged landscape. Santa Rosa, CA: Informing Science Press,.

Gill, T. G., \& Bhattacherjee, A. (2007). The informing sciences at a crossroads: The role of the client. Informing Science: The International Journal of an Emerging Transdiscipline, 10, 17-39. Retrieved from http://www.inform.nu/Articles/Vol10/ISJv10p017-039Gill317.pdf

Gill, T. G. \& Hevner, A. (2013). A fitness-utility model for design science research. ACM Transactions on Management Information Systems, 4(2), Article 5.

Gill, T. G. \& Hicks, R. (2006). Task complexity and informing science: A synthesis. Informing Science: The International Journal of an Emerging Transdiscipline, 9, 1-30. Retrieved from http://www.inform.nu/Articles/Vol9/v9p001-030Gill46.pdf

Gill, T. G., \& Murphy, W. (2011). Task complexity and design science. 9th International Conference on Education and Information Systems, Technologies and Applications (EISTA 2011), Orlando, FL.

Glimcher, P. W., Fehr, E., Camerer, C., \& Poldrack, R. A. (Eds.). (2009). Neuroeconomics: Decision making and the brain. Amsterdam, Netherlands: Academic Press.

Goel, V., \& Grafman. J. (2000). Role of the right frontal cortex in ill-structured planning. Cognitive Neuropsychology, 17, 415-436.

Greenberg, J., \& Dickelman, G. (2000). Distributed cognition: A foundation for performance support. Performance Improvement, 39(6), 18-24.

Gregor, S., \& Hevner, A. (2013). Positioning and presenting design science research for maximum impact. Management Information Systems Quarterly, 37(2), 337-356.

Harris, M., Collins, R., \& Hevner, A. (2009). Control of flexible software development under uncertainty. Information Systems Research: Special Issue on Flexible and Distributed Information Systems Development, 20, 400-419.

Hevner, A., \& Chatterjee, S. (2010). Design research in information systems: Theory and practice, Integrated series in information systems, Vol. 22, New York, NY: Springer.

Hevner, A., March, S., Park, J., \& Ram, S. (2004). Design science research in information systems. Management Information Systems Quarterly, 28(1), 75-105.

Howard-Jones, P., Blakemore, S., Samuel, E., Summers, I., \& Claxton, G. (2005). Semantic divergence and creative story generation: An fMRI investigation. Cognitive Brain Research, 25, 240-250.

Hungerford, B., Hevner, A., \& Collins, R. W. (2004). Reviewing software diagrams: A cognitive study. IEEE Transactions on Software Engineering, 30(2), 82-96.

Hutchins, E. (1995). How a cockpit remembers its speeds. Cognitive Science, 19, 265-288.

Kahneman, D. (2011). Thinking, fast and slow. New York, NY: Farrar, Straus, and Giroux.

Kauffman, S. A. (1993). The origins of order. Oxford UK: Oxford University Press.

Kounios, J., Frymiare, J., Bowden, E., Fleck, E., Subramaniam, K., Parrish, T., \& Jung-Beeman, M. (2006). The prepared mind: neural activity prior to problem presentation predicts subsequent solution by sudden insight. Psychological Science, 17(10), 882-890.

Kuechler, B. and Vaishnavi, V. (2008). On theory development in design science research: Anatomy of a research project. European Journal of Information Systems, 17(5), 489-504.

Kuechler, B., \& Vaishnavi, V. (2011). Promoting relevance in IS research: An informing system for design science research. Informing Science: The International Journal of an Emerging Transdiscipline, 14, 125-138. Retrieved from http://www.inform.nu/Articles/Vol14/ISJv14p125-138Kuechler570.pdf 
Lieberman, M. (2007). Social cognitive neuroscience: A review of core processes. Annual Review of Psychology, 58, 259-289.

Maguire, E. Gadian, D. Johnsrude, I., Good, C., Ashburner, J., Frackowiak, R., \& Frith, C. (2000). Navigation-related structural change in the hippocampi of taxi drivers. Proceedings of the National Academy of Sciences, 97(8), 4398-4403.

Marcus, G. (2013). The three-billion-dollar brain. The New Yorker, March 12. Accessed at http://www.newyorker.com/online/blogs/newsdesk/2013/03/brain-research-national-institutes-healthobama.html?mbid=nl_Daily\%20(198)

Marguc, J., Förster, J. \& Van Kleef, G. (2011). Stepping back to see the big picture: When obstacles elicit global processing. Journal of Personality and Social Psychology, 101(5), 883-901.

Mihov, K., Denzler, M., \& Förster, J. (2010). Hemispheric specialization and creative thinking: A metaanalytic review of lateralization of creativity. Brain and Cognition, 72, 442-448.

Mills, H. (1983). Software productivity. Boston, MA: Little, Brown and Company.

Nardi, B. (1996). Studying context: A comparison of activity theory, situated action models, and distributed cognition. In B. Nardi (Ed.) Context and consciousness: Activity theory and human-computer interaction (pp. 35-52). Cambridge, MA: MIT Press.

Newell, A., \& Simon, H. A. (1972). Human problem solving. Englewood Cliffs, NJ: Prentice, Hall.

Orlikowski, W., \& Iacono, C. (2001). Research commentary: Desperately seeking the 'IT' in IT research. Information Systems Research. 12(2), 121-134.

Ouchi, W. (1979). A conceptual framework for the design of organizational control mechanisms. Management Science, 25(9), 833-848.

Parasuraman, R., Warm, J., \& See, J. (1998). Brain systems of vigilance. In R. Parasuraman (Ed.), The attentive brain (pp. 221-256). Cambridge, MA: MIT Press.

Paulus, P., Levine, D., Brown, V., Minai, A., \& Doboli, S. (2010). Modeling ideational creativity in groups: Connecting cognitive, neural, and computational approaches. Small Group Research, 41(6), 688-724.

Politzer, P. (2008). Neuroeconomics: A guide to the new science of making choices. Oxford, UK: Oxford University Press.

Rhodes, M. (1961). An analysis of creativity. Phi Delta Kappan, 42(7), 305-310.

Rhodes, M. (1987). An analysis of creativity. In S. Isaksen (Ed), Frontiers of creativity research: Beyond the basics. (pp. 216-222). Buffalo, NY: Bearly Limited Publishing.

Ridley, M. (2010). The rational optimist, New York, NY: Harper.

Riedl, R. (2009). Zum Erkenntnispotenzial der kognitiven neurowissenschaften fur die wirtschaftsinformatick: Uberlegungen anhand exemplarischer anwendungen [For finding potential of cognitive neuroscience for business computer science: Considerations based on exemplary applications]. NeuroPsychoEconomics, 4, 32-44.

Riedl, R., Banker, R. D., Benbasat, I., Davis, F. D., Dennis, A. R., Dimoka, A., ... \& Weber, B. (2010). On the foundations of NeuroIS: Reflections on the Gmunden retreat 2009. Communications of the AIS, 27(1: Article 15), 243-264.

Sanfey, A., Loewenstein, G., Mcclure, S., \& Cohen, J. (2006). Neuro-economics: Cross-currents in research on decision-making. Trends in Cognitive Sciences, 10, 108-116.

Santanen, E., Briggs, R., \& de Vreede, G. (2004). Causal relationships in creative problem solving: Comparing facilitation interventions for ideation. Journal of Management Information Systems, 20(4), 167197.

Sarasvathy, S. (2003). Entrepreneurship as a science of the artificial. Journal of Economic Psychology 24, 203-220. 
Satzinger, J., Garfield, M., \& Nagasunduram, M. (1999). The creative process: The effects of group memory on individual idea generation. Journal of Management Information Systems, 15(4), 143-160.

Seidel, S., Müller-Wienbergen, F., \& Becker, J. (2010). The concept of creativity in the information systems discipline: Past, present and prospects. Communications of the Association for Information Systems, 27(1), 217-243.

Simon, H. (1996). The sciences of the artificial (3rd ed.). Cambridge, MA: MIT Press.

Srinivasan, N. (2007). Cognitive neuroscience of creativity: EEG based approaches. Methods, 42, 109-116.

Vom Brocke, J., Riedl, R. \& Leger, P. (2012). Application strategies for neuroscience in information systems design science research. Journal of Computer Information Systems, 52, 4.

Weedman, J. (2008). Client as designer in collaborative design science research projects: What does social science design theory tell us? European Journal of Information Systems, 17(5), 476-488.

Weick, K., Sutcliffe, K., \& Obstfeld, D. (2005). Organizing and the process of sensemaking. Organization Science, 16(4), 409-421.

Winter, R. (2008). Design science research in Europe. European Journal of Information Systems, 17(5), 470-475.

Wood, R. (1986). Task complexity: Definition of the construct. Organizational Behavior and Human Decision Processes, 37, 60-82.

Woolley, A., Hackman, J., Jerde, T., Chabris, C., Bennett, S., \& Kosslyn, S. (2007). Using brain-based measures to compose teams: How individual capabilities and team collaboration strategies jointly shape performance. Social Neuroscience, 2(2), 96-105.

\section{Biographies}

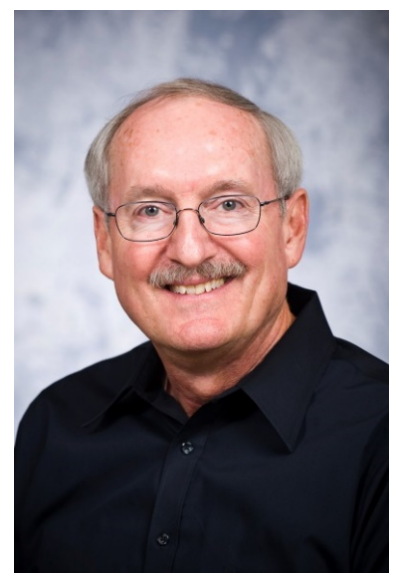

Alan R. Hevner is an Eminent Scholar and Professor in the Information Systems and Decision Sciences Department in the College of Business at the University of South Florida. He holds the Citigroup/Hidden River Chair of Distributed Technology. Dr. Hevner's areas of research interest include design science research, information systems development, software engineering, distributed database systems, healthcare systems, and service-oriented computing. He has published over 200 research papers on these topics and has consulted for a number of Fortune 500 companies. Dr. Hevner received a Ph.D. in Computer Science from Purdue University. He has held faculty positions at the University of Maryland and the University of Minnesota. Dr. Hevner is a Fellow of the American Association for the Advancement of Science (AAAS) and is a member of ACM, IEEE, AIS, and INFORMS. From 2006 to 2009, he served as a program manager at the U.S. National Science Foundation (NSF) in the Computer and Information Science and Engineering (CISE) Directorate. 


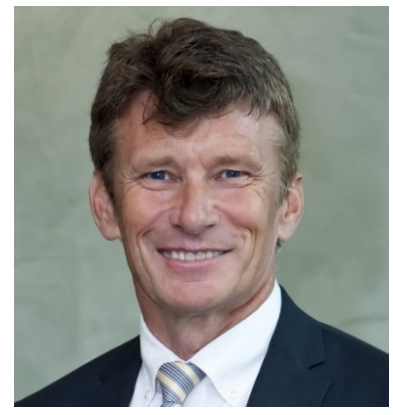

Christopher Davis is an Associate Professor in the Information Systems and Decision Sciences Department at the University of South Florida Saint Petersburg. He holds a doctorate in Information Systems from the University of the West of England, UK. His research explores the way designers and users make sense of information systems and technologies, and their impacts on the expertise of communities of practice. His work has been published in a range of journals including Communications of the ACM, Information Systems Management, the Information Systems Education Journal and the MIS Quarterly.

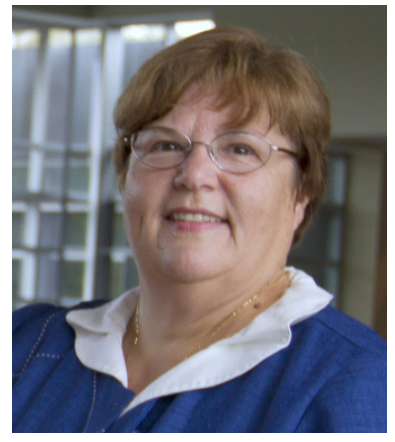

Rosann Webb Collins is Associate Professor of Information Systems and Decision Sciences at the University of South Florida and is Faculty Director of the MBA and EMBA Programs. Her current research includes work on systems development, the impact of information technologies on work, and behavioral issues in information markets. Her publications include a book, Crossing Boundaries: The Deployment of Global IT Solutions, and research articles in MIS Quarterly, Information Systems Research, IEEE Transactions on Software Engineering, IEEE Software, the Journal of the American Society for Information Science, and other MIS and information science publications.

Grandon Gill is a Professor in the Information Systems and Decision Sciences department at the

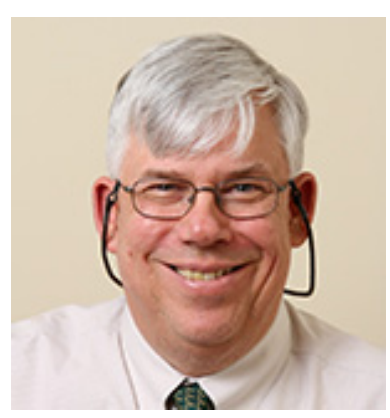
University of South Florida. He holds a doctorate in Management Information Systems from Harvard Business School, where he also received his M.B.A. His principal research areas are the impacts of complexity on decision-making and IS education, and he has published many articles describing how technologies and innovative pedagogies can be combined to increase the effectiveness of teaching across a broad range of IS topics. Currently, he is Editor-inChief of Informing Science: The International Journal of an Emerging Transdiscipline and an Editor of the Journal of IT Education. 